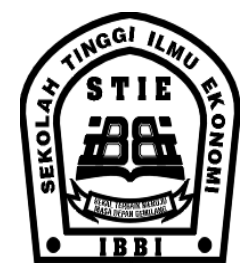

\title{
ANALISIS KAPABILITAS APARAT PENGAWASAN INTERNAL PEMERINTAH (APIP) MENGGUNAKAN STANDART INTERNAL AUDIT CAPABILITY MODEL (IA-CM) (STUDI KASUS PADA INSPEKTORAT KOTA TEBING TINGGI) PERIODE 2017-2018
}

\author{
Muhammad Fahmi \\ Program Studi : S-1 Akuntansi STIE IBBI Medan \\ Delvi Ratna Sari \\ Program Studi : S-1 Akuntansi Universitas Muhammadiyah Sumatera Utara
}

\begin{abstract}
Abstrak / Abstract
Penelitian ini bertujuan menganalisis tingkat Kapabilitas Aparat Pengawasan Internal Pemerintah (APIP) pada inspektorat Kota Tebing Tinggi dengan menggunakan standart yang berlaku universal diseluruh dunia yaitu Internal Audit Capability Model (IA-CM) yang di bentuk oleh Auditor Sektor Publik Dunia yaitu The Institude of Internal Auditor, elemen-elemen internal audit yang mempengaruhi ketertinggalan Kapabilitas APIP dan strategi untuk meningkatkan Kapabilitas APIP Inspektorat Kota Tebing Tinggi. Penelitian ini menggunakan pendekatan penelitian deskriptif. Dalam hal menganalisis data penelitian penulis melakukan teknik pengumpulan data Observasi, dokumentasi dan wawancara. Sedangkan teknik analisi data yang digunakan adalah metode analisis deskriptif. Berdasarkan hasil penelitian berdasarkan penilaian Kapabilitas APIP menggunakan standart Internal Audit Capability Model (IA-CM) menunjukkan bahwa Inspektorat Kota Tebing Tinggi berada pada level 3 dengan catatan perbaikan (Integrated). Dari 6 elemen internal audit sesuai Standart IA-CM, 4 elemen yaitu elemen "Peran dan Layanan APIP (Service and Role of Internal Auditing)", "Pengelolaan Sumber Daya Manusia (People Management)", "Budaya dan Hubungan Organisasi (Organization Relationship and Culture)" dan elemen "Struktur Tata Kelola (Governance Structure)" sudah mencapai level 3 sedangkan 2 elemen lain nya yaitu elemen "Paktik Profesional (Profesional Practice)" dan elemen " Akuntabilitas dan Manajemen Kinerja (Performance Management and Accountability)" masih mencapai level 2. Dari 6 elemen tersebut diketahui elemen yang mempengaruhi ketertinggalan Kapabilitas APIP pada Inspektorat Kota Tebing Tinggi adalah elemen yang masih berada pada level 2
\end{abstract}

Kata Kunci :Tingkat Kapabilitas Aparat Pengawasan Internal Pemerintah (APIP), Internal Audit Capbility Model (IA-CM). 

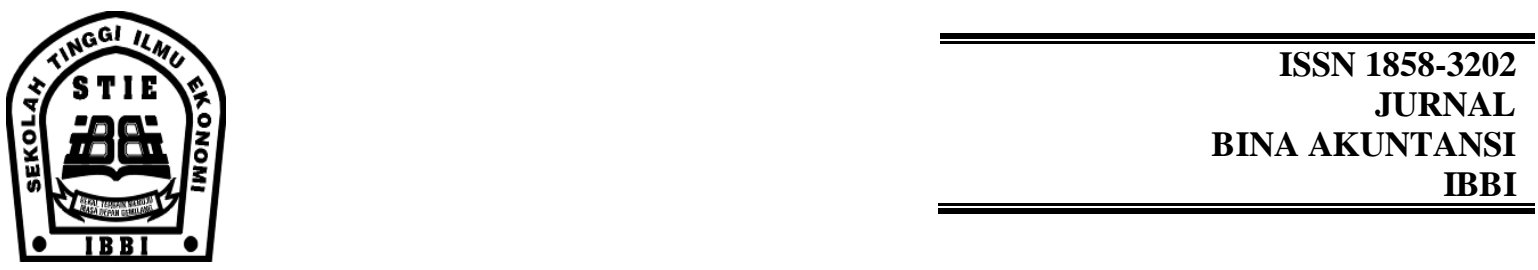

This study aims to analyze the level of the Capability of Government Internal Supervisory Apparatus (APIP) at the Inspectorate of Tebing Tinggi City by using the universal universal standard that is Internal Audit Capability Model (IA-CM) formulated by the World Public Sector Auditor, The Institude of Internal Auditor, internal audit elements that affect the lag of APIP Capability and strategies to improve APIP Capability Inspektorat Kota Tebing Tinggi. This research uses descriptive research approach. In terms of analyzing research data the authors perform Observation data collection techniques, documentation and interviews. While the data analysis technique used is descriptive analysis method. Based on the results of the study based on the APIP capability assessment using the standard Internal Audit Capability Model (IA-CM) indicates that the Inspectorate Kota Tebing Tinggi is at level 3 with an improved record (Integrated). Of the 6 internal audit elements according to Standards IA-CM, the 4 elements are "Service and Role of Internal Auditing", "People Management," "Culture and Organizational Relations (Organization Relationship and Culture) "and the element of" Governance Structure "has reached level 3 while the other 2 elements are" Professional Practice "and the" Performance Management and Accountability "element still reaches the level 2. Of the 6 elements are known elements affecting the lag of APIP Capability at City Inspectorate Tebing Tinggi is an element that is still at level 2

Keywords :Level of Capability of Aparat Pengawasan Internal Pemerintah(APIP), Internal Audit Capability Model (IA-CM). 


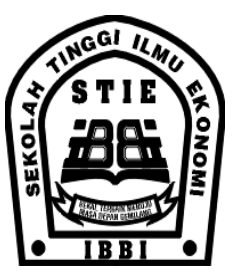

\section{PENDAHULUAN}

Dalam Konferensi Nasional Aparat Pengawasan Intern Pemerintah, Peserta KN APIP menyatakan saat ini di Indonesia terdapat permasalahan Nasional kualitas Laporan Keuangan Pemerintah belum baik, efesiensi dan efektifitas pengelolaan Keuangan Negara belum optimal dan masih tingginya praktik Korupsi, Kolusi dan Nepotisme (KKN), maka peran Aparat Pengawasan Intern Pemerintah (APIP) yang efektif merupakan salah satu tonggak paling penting dalam upaya mewujudkan pemerintah dengan tata kelola yang baik (good governancel) dan pemerintah yang bersih (good government). Peran APIP berdasarkan Peraturan Pemerintah Nomor 60 tahun 2008 tentang Sistem Pengendalian Intern Pemerintah pasal 11 yakni : a). Memberikankeyakinan yang memadai atas ketaatan,kehematan, efisiensi, dan efektivitas pencapaiantujuan penyelenggaraan tugas dan fungsi InstansiPemerintah;b).memberikan peringatan dini dan meningkatkanefektivitas manajemen risiko dalampenyelenggaraantugas dan fungsi Instansi Pemerintah; danc). memelihara dan meningkatkan kualitas tata kelolapenyelenggaraan tugas dan fungsi InstansiPemerintah.

Peran yang efektif dari Aparat Pengawasan Intern Pemerintah (APIP) diharapkan dapat menjamin agar penyelenggaraan urusan pemerintah daerah dilaksanakan secara tertib, efesien dan efektif sesuai dengan rencana dan ketentuan peraturan perundang-undangan dan juga dapat mewujudkan pemerintahan yang baik, bersih dan berwibawa, bebas dari penyimpangan dan

penyalahgunaan kekuasaan serta praktikpraktik korupsi, kolusi dan nepotisme (KKN). Elieser (2016).

Dalam Pasal 47 PP Nomor 60 Tahun 2008 dinyatakan bahwa pihak yang mnejalankan pengawasan Intern atas penyelenggaraan tugas dan fungsi instansi pemerintah termasuk akuntabilitas keuangan negara adalah Aparat Pengawasan Intern Pemerintah (APIP). Dalam melaksanakan tugasnya APIP melaksanakan kegiatan pengawasan berupa audit, reviu, evaluasi, pemantauan dan kegiatan pengawasan lainnya dalam rangka memberikan keyakinan yang memadai bahwa kegiatan telah dilaksakan secara efektif dan efesien dalam mewujudkan (Good Government) tata pemerintahan yang baik.

Seiring dengan berkembangnya auditor sektor publik di dunia, The Institute of Internal AuditorResearch Foundation (IIARF) selaku organisasi profesi auditor intern dunia mengembangkan kerangka kerja yang dikenal dengan Internal Audit Capability Model (IACM). IACM mengidentifikasi aspek-aspek fundamental yang dibutuhkan bagi pengembangan audit intern yang efektif yang mencakup elemen-elemen yang diperlukan audit internal yang efektif di Sektor Publik. Adapun elemen-elemen audit internal tersebut adalah :
a. Peran dan Layanan APIP (Service and Role of Internal Auditing)
b. Pengelolaan SDM (People Management)
c. Praktik Profesionnal (Profesional Practice)
d. Akuntabilitas dan Manajemen Kinerja (Performance Management and Accountability)

e. Budaya dan Hubungan Organisasi (Organization Relationship and Culture)

f. Struktur Tata Kelola (Governance Structure)

BPKP dalam PK BPKP Nomor 6 Tahun 2015 tentang Grand Design Peningkatan Kapabilitas Aparat Pengawasan Intern Pemerintah 2015-2019 dan Peraturan Kepala BPKP Nomor 16 Tahun 2015 tentang Teknis Peingkatan Kapabilitas Aparat Pengawasan Intern Pemerintah mengadopsi kerangka kerja IACM tersebut sebagai dasar penilaian Kapabilitas Aparat Pengawasan Internal Pemerintah (APIP) di Indonesia.

Pemerintah melalui Rencana Pembangunan Jangka Menengah Nasional (RPJMN) 2015-2019 menargetkan kapabilitas APIP di tahun 2019 berada pada level 3 dari skor level 1-5 sesuai kriteria penilaian internasional menggunakan konsep penilaian IA-CM. Sementara itu kondisi tingkat kapabilitas APIP saat ini sebagian besar $(85,23 \%)$ masih berada pada level 1

Berdasarkan publikasi BPKP tahun 2014 hasil penelitian tingkat kapabilitas APIP 


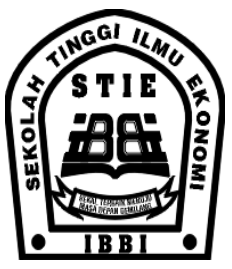

terdapat 474 APIP K/L/D per 31 Desember 2014, sebanyak 404 unit APIP atau 85,23\% berada pada level 1, 69 unit APIP atau 14,56\% unit APIP berada pada level 2 dan baru satu unit APIP atau $0,21 \%$ yang berada pada level 3.

Tabel 1.1Kondisi dan Target Peningkatan Kapabilitas APIP

\begin{tabular}{|c|c|c|c|c|c|c|c|c|c|c|c|c|c|c|c|}
\hline \multirow[b]{2}{*}{ Unit APP } & \multicolumn{4}{|c|}{ Kondisis s.d2014 } & \multicolumn{5}{|c|}{ Target Tahunan Lerel 2} & \multicolumn{6}{|c|}{ Target Tahunan Lerel 3} \\
\hline & $\begin{array}{c}\text { Lerel } \\
1\end{array}$ & $\begin{array}{c}\text { Lerel } \\
2\end{array}$ & Lerel & Jumla & 2015 & 2016 & 201 & 2018 & 2019 & 2015 & 2016 & 2017 & & 2019 & $\begin{array}{c}\text { s.d } \\
2024\end{array}$ \\
\hline $\mathrm{K} / \mathrm{L}$ & 66 & 19 & 1 & 86 & 3 & 18 & 13 & 17 & 8 & 4 & 13 & 16 & 19 & 17 & 86 \\
\hline Provinsi & 28 & 6 & & 34 & 1 & 4 & 7 & 10 & 2 & 2 & 2 & 6 & 7 & 9 & 34 \\
\hline $\mathrm{Kab} / \mathrm{Kota}$ & 310 & 4 & & 354 & 32 & 24 & 28 & 22 & 25 & 10 & 30 & 40 & 32 & 16 & 354 \\
\hline Jumlah & 404 & 69 & 1 & 474 & 36 & 46 & 48 & 49 & 35 & 16 & 45 & 62 & 80 & 42 & 474 \\
\hline
\end{tabular}

Sumber : Grand Design Kapabilitas APIP 2015-2019

Masih rendanya tingkat level Kapabilitas Aparat Pengawasan Internal Pemerintah (APIP) menunjukkan bahwa kualitas Auditor Internal Pemerintah masih belum optimal dalam melaksanakan tugasnya dalam bentuk pengawasan yang berupa audit, reviu, pemantauan dan evaluasi hingga tidak dapat mewujudkan tata pemerintah yang baik sesuai tujuan organisasi.

PP 192 tahun 2014 tentang BPKP pasal 3 huruf $\mathrm{J}$ dalam melaksanakan tugasnya BPKP melaksanakan fungsi "Pembinaan Kapabilitas Pengdendalian Intern Pemerintah dan sertifikat Jabatan Fungsional Auditor" maka dalam penelitian ini akan menganalisi kapabilitas APIP berdasarkan standart Internal Audit Capability Model (IACM) yang menyatakan elemen-elemen kapabilitas APIP sebagai dasar penilaian tingkat level kapabilitas APIP.

Berdasarkan latar belakang dan uraian ini, maka penelitian ini mengambil judul"Analisis Kapabilitas Aparat Pengawasan Intern Pemerintah (APIP) dengan menggunakan Standart Internal Audit Capability Model (IA-CM) (Studi Kasus pada Inspektorat Kota Tebing Tinggi)".

\section{Identifikasi Masalah}

Berdasarkan latar belakang masalah, maka dengan ini permasalahan yang diperoleh adalah "Masih rendahnya tingkat level kapabilitas APIP (Aparat Pengawasan Internal Pemerintah) tidak dapat mewujudkan pemerintahan yang baik, bersih dan berwibawa, bebas dari penyimpangan dan penyalahgunaan kekuasaan serta praktikpraktik korupsi, kolusi dan nepotisme (KKN)".

\section{Rumusan Masalah}

Dalam melaksanakan penelitian penulis merumuskan masalah sebagai berikut :

a. Bagaimana tingkat kapabilitas APIP pada Inspektorat Kota Tebing Tinggi dengan mengacu pada standart IA-CM?

b. Pada elemen manakah yang mempengaruhi ketertinggalan APIP yang tidak dapat mencapai target?

c. Bagaimana strategi yang dilakukan untuk meningkatan kapabilitas APIP yang belum maksimal?

\section{Tujuan Penelitian}

Berdasarkan perumusan masalah tersebut, penelitian ini dilakukan dengan tujuan sebagai berikut:

a. Menganalisis tingkat Kapabilitas APIP pada Inspektorat Kota Tebing Tinggi dengan mengacu pada standart IA-CM.

b. Menganalisis elemen yang mempengaruhi ketertinggalan Kapabilitas APIP Pada Inspektorat Tebing Tinggi.

c. Mengetahui strategi yang dilakukan untuk meningkatan kapabilitas APIP yang belum maksimal.

\section{Kegunaan Penelitian}

Penelitian ini diharapkan dapat memberikan manfaat bagi pihak-pihak yang berkepentingan :

a. Bagi peneliti, penelitian untuk memberikan wawasan penulis dalam hal Audit Internal Pemerintah khususnya peningkatan Kapabilitas APIP berdasarkan IA-CM.

b. Bagi Inspektorat Kota Tebing Tinggi, dengan penelitian ini dapat dijadikan masukan oleh Inspektorat dalam upaya peningkatan Kapabilitas APIP.

c. Bagi Akademis dan Peneliti lain nya, penelitian ini dapat menjadi bahan referensi untuk melakukan penelitian lebih kanjut tentang Kapabilitas APIP. 


\section{TINJAUAN LITERATUR}

\section{Audit Internal}

Evaluasi adalah suatu proses untuk Internal Audit adalah agen yang paling "pas" untuk mewujudkan Internal Control, Risk Management dan Good Corporate Governance yang pastinya akan memberikan Nilai Tambah bagi SDM dan Perusahaan (Valery G. Kumaat, 2010, Hal. 35)

The Institute of Internal Auditors Research Foundation (IIARF) menjelaskan bahwa Internal Audit menyatakan tujuan mendasar, sifat, dan ruang lingkup audit internal yang di uraikan sebagai berikut :

"Audit internal adalah kegiatan assurance dan konsultasi independen yang bertujuan untuk menambah nilai dan memperbaiki operasi organisasi. Ini membantu organisasi mencapai tujuannya dengan membawa pendekatan sistematis dan disiplin untuk mengevaluasi dan meningkatkan efektivitas proses manajemen, pengendalian, dan tata kelola risiko".

Menurut American Accounting Association dalam buku auditing oleh Guy, dkk (2005), mendifinisikan bahwa

"Audit Internal adalah proses sistematis yang secara obyektif memperoleh dan mengevaluasi asersi mengenai tindakan dan kejadian-kejadian ekonomis untuk meyakinkan derajat kesesuaian antara asersi ini dengan kreteria yang ditetapkan ke pengguna yang berkepentingan".

\section{Aparat Pengawasana Internal Pemerintah (APIP)}

Sebagaimana dimaksud dalamPasal 4 huruf g pada PP 60 Nomor 60 tahun 2008 sekurang-kurangnya perwujudan peran aparat pengawasan internpemerintah yang efektifmemelihara dan meningkatkan kualitas tata kelolapenyelenggaraan tugas dan fungsi InstansiPemerintah.

Standart Audit Aparat Pengawasan Internal Pemerintah mendefinisikan "Pengawasan internal pemerintah merupakan fungsi manajemen yang penting dalam penyelenggaraan pemerintahan. Melalui pengawasan intern dapat diketahui apakah suatu instansi pemerintah telah melaksanakan kegiatan sesuai dengan tugas dan fungsinya secara efektif dan efisien, serta sesuai dengan rencana, kebijakan yang telah ditetapkan, dan ketentuan. Selain itu, pengawasan intern atas penyelenggaraan pemerintahan diperlukan untuk mendorong terwujudnya good governance dan clean government dan mendukung penyelenggaraan pemerintahan yang efektif, efisien, transparan, akuntabel serta bersih dan bebas dari praktik korupsi, kolusi, dan nepotisme".

Dalam Standart Audit Aparat Pengawasan Internal Pemerintah mengatakan pengawasan Internal adalah

"Seluruh proses kegiatanaudit, reviu, evaluasi, pemantauan, dan kegiatanpengawasan lain terhadap penyelenggaraan tugasdan fungsi organisasi dalam rangka memberikankeyakinan yang memadai bahwa kegiatan telahdilaksanakan sesuai dengan tolok ukur yang telahditetapkan secara efektif dan efisien untukkepentingan pimpinan dalam mewujudkan tatakepemerintahan yang baik".

Dalam PP 60 Tahun 2008 tentang SPIP mengatakana Aparat Pengawasan Intern Pemerintah (APIP)adalah Instansi Pemerintah yang mempunyai tugas pokok dan fungsi melakukan pengawasan, dan terdiri atas:

a. Badan Pengawasan Keuangan dan Pembangunan (BPKP) yang bertanggung jawab kepada Presiden;

b. Inspektorat Jenderal (Itjen)/Inspektorat Utama (Ittama)/Inspektorat yang bertanggung jawab kepada Menteri/Kepala Lembaga Pemerintah Non Departemen (LPND);

c. Inspektorat Pemerintah Provinsi yang bertanggung jawab kepada Gubernur, dan;

d. Inspektorat Pemerintah Kabupaten/Kota yang bertanggung jawab kepada Bupati/Walikota.

Melalui Peraturan Pemerintah Nomor 60 tahun 2008 dalam pasal 48 ayat 2 mengemukakan bahwa APIP melakukan pengawasan intern melalui :

1. Audit adalah proses identifikasi masalah, analisis, dan evaluasi bukti yang dilakukan secara independen, obyektif dan profesional berdasarkan standar audit, untuk menilai kebenaran, kecermatan, kredibilitas, efektifitas, efisiensi, dan 


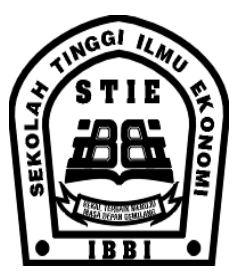

keandalan informasi pelaksanaan tugas dan fungsi instansi pemerintah.Berdasarkan pasal 50 pada Peraturan Pemerintah nomor 60 tahun 2008 tentang SPIP audit yang dimaksud merupakan : a). Audit kinerja yaitu audit atas pengelolaankeuangan negara dan pelaksanaan tugas dan fungsiInstansi Pemerintah yang terdiri atas aspekkehematan, efisiensi, dan efektivitas; dan b). Audit dengan tujuan tertentu mencakup audit yang tidak termasuk dalam auditkinerja. Audit dengan tujuan tertentu antara lain audit investigatif, audit ataspenyelenggaraan SPIP, dan auditatas hal-hal lain di bidang keuangan.

2. Reviu adalah penelaahan ulang buktibukti suatu kegiatan untuk memastikan bahwa kegiatan tersebut telah dilaksanakan sesuai dengan ketentuan, standar, rencana, atau norma yang telah ditetapkan.

3. Pemantauan adalah proses penilaian kemajuan suatu program/kegiatan dalam mencapai tujuan yang telah ditetapkan

4. Evaluasi adalah rangkaian kegiatan membandingkan hasil/prestasi suatu kegiatan dengan standar, rencana, atau norma yang telah ditetapkan, dan menentukan faktor-faktor yang mempengaruhi keberhasilan atau kegagalan suatu kegiatan dalam mencapai tujuan.

Kegiatan utama APIP meliputi audit, reviu, pemantauan, evaluasi, dan kegiatan pengawasan lainnya berupa sosialisasi, asistensi dan konsultansi.Kegiatan audit yang dapat dilakukan oleh APIP pada dasarnya dapat dikelompokkan ke dalam tiga jenis audit berikut iniberdasarkan :

1. Audit atas laporan keuangan

yang bertujuan untuk memberikan opini atas kewajaran penyajian laporan keuangan sesuai dengan prinsip akuntansi yang diterima umum.

2. Audit kinerja

yang bertujuan untuk memberikan simpulan dan rekomendasi atas pengelolaan instansi pemerintah secara ekonomis, efisien dan efektif.
3. Audit dengan tujuan tertentu yaitu audit yang bertujuan untuk memberikan simpulan atas suatu hal yang diaudit. Yang termasuk dalam kategori ini adalah audit investigatif, audit terhadap masalah yang menjadi fokus perhatian pimpinan organisasi dan audit yang bersifat khas.

\section{Perwujudan Peran APIP yang Efektif}

Perwujudan Peran APIP yang efektif berdasarkan PP Republik Indonesia Nomor 60 Tahun 2008 tentang Sistem Pengendalian Internal Pemerintah sekurang-kurangnya harus

1) memberikan keyakinan yang memadai atas ketaatan,kehematan, efisiensi, dan efektivitas pencapaiantujuan penyelenggaraan tugas dan fungsi InstansiPemerintah;

2) memberikan peringatan dini dan meningkatkanefektivitas manajemen risiko dalam penyelenggaraantugas dan fungsi Instansi Pemerintah; dan

3) memelihara dan meningkatkan kualitas tata kelolapenyelenggaraan tugas dan fungsilnstansiPemerintah.

\section{Peningkatan Kapabilitas APIP}

Menurut Kamus Bahasa Indonesia (2014) yang di uraikan oleh Yudhi Setiawan (2015) Kapabilitas adalah "Kapabilitas, artinya juga sama dengan komperensi, yaitu kemampuan, namun pemaknaan kapabilitas tidak sebatas memiliki keterampilan (skill) saja namun lebih dari itu, yaitu lebih paham secara mendetail sehingga benar-benar menguasai kemampuanya dari titik kelemahan hingga cara mengatasinya".

Dalam Lampiran 1 PK BPKP tentang Pedoman teknis Peningkatan Kapabilitas APIP mengatakan Kapabilitas APIP adalah kemampuan untuk melaksanakan tugas-tugas pengawasan yang harus dimiliki APIP agar dapat mewujudkan peran APIP secara efektif, yang terdiri dari tiga unsur yang saling terkait yaitu kapasitas, kewenangan dan kompetensi sumber daya manusia (SDM). Proses peningkatan APIP dilakukan dengan empat tahapan yaitu :

1. Tahap Penilaian Mandiri 


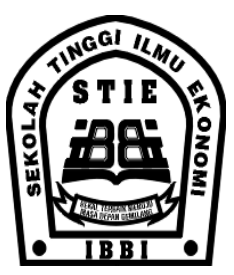

2. Tahap Penjaminan Kualitas oleh BPKP

3. Tahap Peningkatan Kapabilitas APIP berdasarkan identifikasi area yang memerlukan perbaiksn yang diperoleh pada tahap 1

4. Tahap Pemantauan Pelaksanaan Peningkatan Kapabilitas.

Metode yang digunakan dalam menilai kapabilitas APIP adalah dengan penilaian mandiri oleh APIP yang bersangkutan. Penilaian Mandiri (Self Assesement) adalah kegiatan yang dilakukan dalam rangka menilai efektivitas APIP yang tercermin dari level kapabilitasnya dengan mengacu pada praktik tata kelola yang baik dan berlaku secara universal di seluruh dunia melalui penilaian elemen-elemen yang tercantum dalam Internal Audit Capability Model (IACM). (Sumber : Peraturan Kepala BPKP tentang Pedoman Teknis Monitoring Tingkat Kapabilitas Aparat Pengawasan Intern Pemerintah).

\section{Internal Audit Capability Model (IA-CM)}

PP nomor 60 Tahun 2008 menyatakan The Institute of Internat Auditor(IIA) Reasearch Foundation menyatakan tentang IACM merupakan :

"IA-CM adalah kerangka yang mengidentifikasi dasar-dasar yang diperlukan untukaudit internal yang efektif di sektor publik. Ini menggambarkan evolusipath untuk organisasi sektor publik untuk mengikuti dalam mengembangkan efektifaudit internal untuk memenuhi kebutuhan tata kelola organisasi dan guru besarharapan sional. IACM menunjukkan langkah-langkah dalam maju dari tingkatdari audit internal yang khas dari organisasi kurang mapan untuk yang kuat,efektif, kemampuan audit internal umumnya terkait dengan lebih matangdan organisasi yang kompleks".

IA-CM oleh The Instituted of Internal Auditor (IIA) Reasearch Foundation berfungsi untuk :

1. Menentukan persyaratan audit internal sesuai dengan sifat, kompleksitas, dan terkaitrisiko operasinya.

2. Menilai ada kemampuan audit internal terhadap persyaratan yang telah ditentukan.

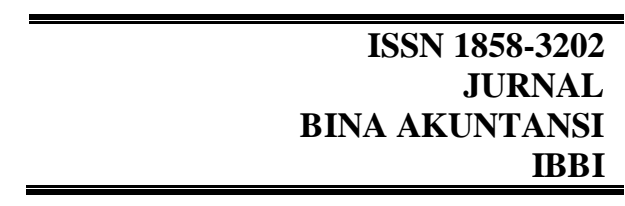

3. Mengidentifikasi kesenjangan tidak bisa signifi antara persyaratan dan adakemampuan audit internaldan bekerja untuk mengembangkan tingkat yang sesuai kemampuan audit internal

Tahap pertama dalam peningkatan kapabilitas APIP adalah pelaksanaan Penilaian Mandiri (self assessment) untuk mengetahui tingkat kapabilitasnya pada saat penilaian tersebut dilakukan. Kerangka Pikir peniliaian mandiri yang diterapkan di Indonesia mengacu kepada Internal Audit Capability Model (IACM) yang dikembangkan oleh The Insttitue Of Internal Auditor (IIA) yang telah dilakukan penyesuaian, sehingga lebih mudah dipahami dalam pelaksanaannya.

Pelaksanaan penilaian mandiri pada level tertentu mencakup penilaian terhadap 6 elemen, yang meliputi :

1. Peran dan Layanan APIP (Service and Role of Internal Auditing)

2. Pengelolaan SDM (People Management)

3. Praktik Profesionnal (Profesional Practice)

4. Akuntabilitas dan Manajemen Kinerja (Performance Management and Accountability)

5. Budaya dan Hubungan Organisasi (Organization Relationship and Culture)

6. Struktur Tata Kelola (Governance Structure)

\section{Elemen - Elemen Audit Internal}

Adapun elemen-elemen Audit Internal yang dikembangkan oleh The Institute of Internal Auditor (IIA) Research Foundation yang kemudian di adopsi oleh BPKP dalam PK BPKP tentang Pedoman teknis Peningkatan Kapabilitas APIP adalah :

1) Peran dan Layanan APIP (Service and Role of Internal Auditing)

Peran APIP adalah memberikan penilaian yang independen dan objektif dalam rangka membantu organisasi untuk mencapai tujuan dan memperbaiki operasi dan mengembangkan manajemen ke arah yang lebih baik.

Jenis layanan yang diberikan APIP pada umumnya didasarkan pada kebutuhan organisasi, kewenangan, ruang lingkup dan kapasitas APIP. Layanan 


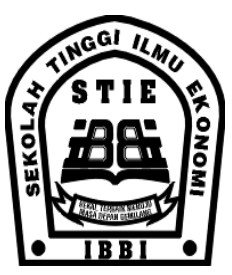

mencakup kegaiatan pemberian jasa penjamin (assurance) yang terdiri dari audit, reviu dan evaluasi dimana kegiatan audit antara lain dapata berupa audit atas transaksi, kepatuhan kinerja dan value for money audit, dan pemberian saran (Advisory Service) yang mencakup kegiatan pelatihan reviu pengembangan sistem, penilaian mandiri atas pengendalian (control self assessment), dan pemberian nasihat lain (tanpa mengambil alih tugas dan tanggung jawab manajemen).

2) Pengelolaan Sumber Daya Manusia (People Management)

Manajemen SDM merupakan suatu proses mulai dari merekrut, menempatkan, mengembangkan kompetensi dan karir SDM, memberikan insentif, sampai dengan menciptakan lingkungan kerja yang kondusif yang memungkinkan pegawai untuk memberikan kemampuan terbaik mereka secara optimal.

3) Paktik Profesional (Profesional Practice)

Penilaian pada elemen Paktik Profesional mencakup penilaian terhadap kapasitas APIP yang mencakup kebijakan, proses dan prakti-praktik yang memungkinkan APIP bekerja secara efektif dengan melihat keselarasan antara kebijakan, proses dan prakti-praktik APIP dengan perioritas dan strategi pengelolaan resiko dari K/L/P dimana APIP itu berada.

4) Akuntabilitas dan Manajemen Kinerja (Performance Management and Accountability)

Hal yang dinilai adalah kegiatan dan upaya APIP dalam menyediakan infoemasi kinerja yang dibutuhkan, baik informasi kinerja keuangan maupun non keuangan, dalam mengelola, melaksanakan, dan mengendalikan opersional APIP dan mempetanggungjawabkan kinerja dan hasil yang diperoleh APIP.

5) Budaya dan Hubungan Organisasi (Organization Relationship and Culture)

Penilaian ini bertujuan untuk meyakinkan bahwa budaya dan hubungan
ISSN 1858-3202

JURNAL

BINA AKUNTANSI

IBBI
Internal APIP dalam organisasi sebagaimana terlihat pada struktur organisasi dan manajemen internal. Melihat apakah hubungan APIP dengan pimpinan unit lain di K/L/P dimana APIP tersebut berada terjalin dengan baik.

6) Struktur Tata Kelola (Governance Structure)

Penilaian ini untuk menilai apakah APIP telah memiliki kebijakan dan proses yang memadai untuk memberikan otoritas yang diperlukan, dukungan dan sumber daya untuk pelaksanaan pengawasan intern serta hubungan pelaporan secara administratif dan fungsional sebagai sara terjaminnya independensi dan Objektivitas APIP

\section{Level Kapabilitas APIP}

Didalam model IACM yang dikembangkan oleh The Institute of Internal Auditor (IIA) Research Foundation, penilaian kapabilitas APIP dibagi menjadi lima level kapabilitas, yaitu Level1(Initial), Level 2 (Infrastructure), Level 3 (Integrated), Level 4 (Managed),danLevel 5 (Optimizing).

Kondisi audit internal pada setiap level IA-CM menurut The Institute of Internal Auditor (IIA) Research Foundation adalah sebagai berikut:

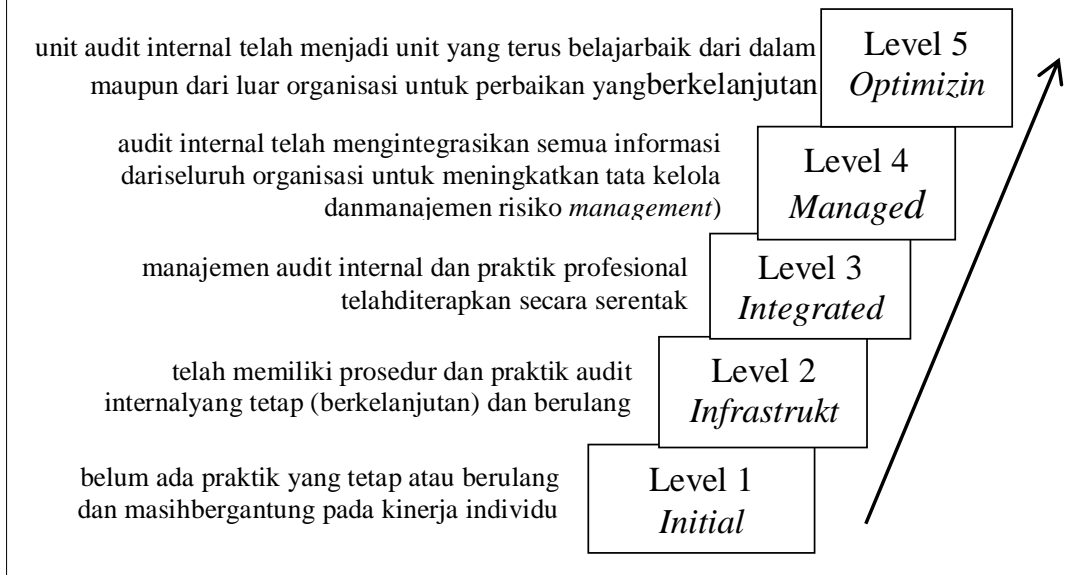

\section{Gambar 1.1 Level Internal Auditor Capability Model (IACM)}




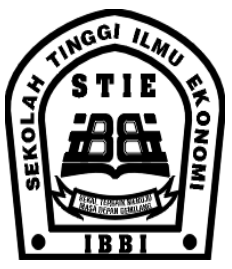

\section{Level 1 (Initial)}

Pada organisasi APIP yang mencapai level 1, dalam pelaksanaan pengawasannya belum atau tidak ada praktik yang tetap atau berulang dan masihbergantung pada kinerja individu Auditor yang dimiliki.

APIP kapabilitas level 1, "Belum dapat memberikan jaminan atas proses tata kelola sesuai peraturan dan mencegah korupsi”.

\section{Level 2 (Infrastructure)}

Pada organisasi APIP yang mencapai level 1, dalam pelaksanaan pengawasannya proses audit dilakukan secara tetap, rutin dan berulang, sudah membangun infrastruktur, namun baru sebagian yang telah selaras dengan standart audit.

APIP kapabilitas level 2, "Telah mampu memberikan keyakinan yang memadai bahwa proses sesuai peraturan, mampu mendeteksi terjadinya korupsi”.

\section{Level 3 (Integrated)}

Pada organisasi APIP yang mencapai level 3, dalam pelaksanaan pengawasannya praktik profesional dan audit internal telah diterapkan secara serentak dan telah selaras dengan standar.

APIP kapabilitas level 3, "Telah mampu menilai efesiensi, efektivitas dan keekonomian suatu program atau kegiatan dan mampu memberikan konsultasi pada tata kelola, menejemen resiko dan pengendalian intern".

\section{Level 4 (Managed)}

Pada organisasi APIP yang mencapai level 4 , dalam pelaksanaan pengawasannya unit audit internal telah mengintergrasikan semua informasi di seluruh organisasi untuk memperbaiki tata kelola dan manajemen resiko.

APIP kapabilitas level 4, "Telah mampu memberikan assurance sacara keseluruhan atas tata kelola, manejemen resiko dan pengendalian intern".

\section{Level 5 (Optimizing)}

Pada organisasi APIP yang mencapai level 5, dalam pelaksanaan pengawasannya unit audit internal telah menunjukkan unit yang terus belajar, baik dari dalam maupun dari luar organisasi untuk perbaikan berkelanjutan.

APIP kapabilitas level 5, "Telah menjadi agen perubahan".

Area Proses Kunci (Key Process Area/KPA)

Dalam rangka peningkatan mandiri (self improvement) kapabilitas, APIP harus menguasai (mastering) dan melembagakan (Institutionalizing) KPA. APIP dapat dikatakan memilik kapabilitas level tertentu ketika APIP telah menguasai dan melembagakan semua KPA level tersebut.

Penguasaan KPA adalah output dan outcome untuk tiap-tiap KPA yang ditargetkan. Langkah ini dilakukan dengan melaksanakan aktivitas esensial/kegiatan penting dalam rangka mencapai tujuan yang telah dirumuskan.

Jumlah KPA setiap level dapat di lihat pada tabel sebagai berikut :

Tabel 1.2 Jumlah KPA setiap Level

\begin{tabular}{|c|c|c|c|c|c|c|c|c|c|}
\hline \multirow{2}{*}{ Elemen } & \multicolumn{8}{|c|}{ Lernyataan } & \multicolumn{2}{c|}{ Level 4 } & \multicolumn{2}{c|}{ Level 5 } & Jumlah \\
\cline { 2 - 10 } & \multicolumn{2}{|c|}{ Level 2 } & \multicolumn{2}{|c|}{ Level 3 } & \multicolumn{2}{c|}{ Lever } \\
\cline { 2 - 9 } & Jumlah & Nomor & Jumlah & Nomor & Jumlah & Nomor & Jumlah & Nomor & Total \\
\hline I & 9 & $1-9$ & 10 & $10-19$ & 5 & $20-24$ & 6 & $25-30$ & 30 \\
\hline II & 12 & $1-12$ & 20 & $13-32$ & 14 & $34-46$ & 9 & $47-55$ & 3 \\
\hline III & 13 & $1-13$ & 17 & $14-30$ & 4 & $31-34$ & 9 & $35-43$ & 43 \\
\hline IV & 10 & $1-10$ & 19 & $11-29$ & 9 & $30-38$ & 5 & $39-43$ & 43 \\
\hline V & 6 & $1-6$ & 14 & $7-20$ & 7 & $21-27$ & 8 & $28-35$ & 35 \\
\hline VI & 8 & $1-8$ & 13 & $9-21$ & 8 & $22-29$ & 5 & $30-34$ & 34 \\
\hline & 58 & & 93 & & 47 & & 42 & & 240 \\
\hline
\end{tabular}




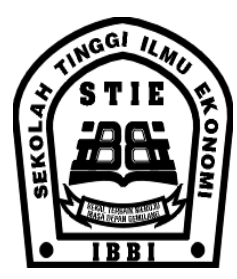

\section{KERANGKA BERFIKIR}

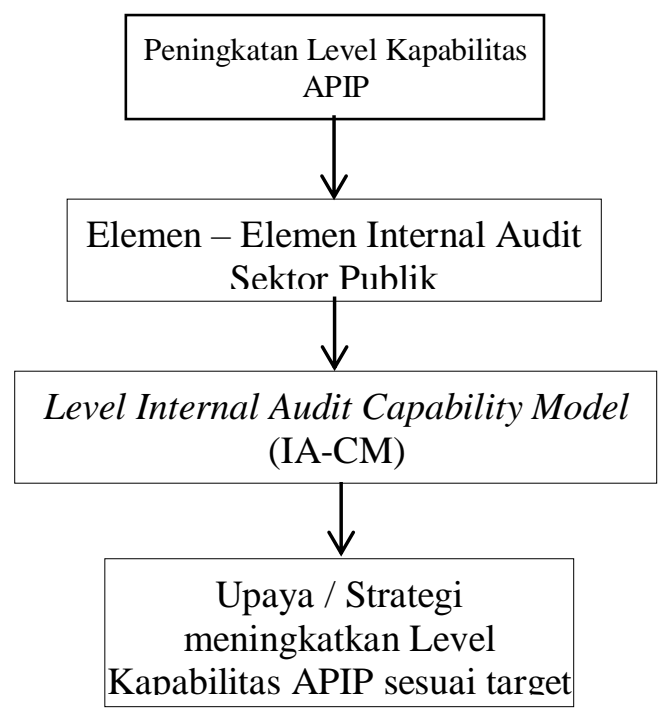

\section{Gambar 1.2 Kerangka Konseptual}

Peningkatan Level Kapabilitas APIP adalah upaya memperkuat, meningkatkan,mengembangkan kelembagaan, tata laksana/proses bisnis/manajemendan sumber daya manusia APIP agar dapat melaksanakan peran danfungsi APIP yang efektif. Badan Pengawasan Keuangan dan Pembangunan mengadopsi standart Internal Audit Capability Model (IA-CM) yang di kembangkan oleh The Instituted of Internal Auditor (IIA) sebagai acuan penilaian Kapabilitas APIP di Indonesia. IA-CM menilai kapabilitas Internal Auditor menggunakan 6 elemen yaitu : 1).Peran dan Layanan APIP; 2) Pengelolaan Sumber Daya; 3) Paktik Profesional; 4) Akuntabilitas dan Manajemen Kinerja; 5) Budaya dan Hubungan Organisasi; 6) Struktur Tata Kelola.Yang dalam 6 elemen tersebut terdapat 41 KPA yang meliputi 240 Pernyataan yang akan dipenuhi oleh APIP. Setelah 240 pernyataan tersebut di isi oleh APIP maka akan diperoleh Level berdasarkan terpenuhi atau tidaknya pernyataan-pernyataan setiap elemen, lalu setelah diperoleh level setiap elemen-elemen tersebut kemudia dari level-level elemen tersebut akan diperoleh pula Level APIP berdasarkan level-level elemen.

Lalu dari level setiap elemen maka dapat di simpulkan lah level kapabilitas suatu APIP yang menggambarkan tahap-tahap kegiatan pengawasan intern yang dilaksanakan unit APIP tealh efektif sesuai dengan pemenughan pernyataan-pernyataan dari setiap KPA pada setiap elemen.

Lalu melalui hasil Penilaian Kapabilitas APIP yang telah menyatakan level APIP maka diuraikan lah upaya atau strategi oleh APIP Inspektorat Kota Tebing Tinggi untuk menanggulangi level APIP yang telah/belum mencapai target atau strategi untuk tahap peningkatan kapabilitas APIP.

\section{METODOLOGI PENELITIAN}

Pendekatan yang dilakukan yaitu pendekatan deskriptif. Menurut Sugiyono (2006, hal. 11) pendekatandeskriptif adalah pendekatan yang dilakukan untuk mengetahui nilai variablemandiri, baik satu variabel atau lebih (independent) tanpa membuatperbandingan, atau menghubungkan dengan variabel lain"

Adapun variabel yang akan diamati dalam penelitian ini yaitu :

1. Aparat Pengawasan Internal Pemerintah (APIP)

Aparat Pengawasan Intern Pemerintah (APIP) adalah instansi pemerintah yangdibentuk dengan tugas melaksanakan pengawasan intern (internal audit) dilingkungan pemerintah pusat dan/atau pemerintah daerah,

2. IA-CM (Internal Audit Capability Model) Internal Audit Capability Model $(I A C M)$, yaitu suatukerangka kerja yang mengindentifikasi aspek-aspek fundamental yangdibutuhkan untuk pengawasan intern yang efektif di sektor publik. IACM menunjukkan langkahlangkahuntuk maju dari tingkat pengawasan intern yang kurang kuat menujukondisi yang kuat dan efektif terkait dengan organisasi yang lebih matang.

3. Level Kapabilitas Aparat Pengawasan Internal Pemerintah

Menilai tingkat kemampuan APIP untuk melaksanakan tugas-tugas pengawasan yang harus dimiliki APIP 


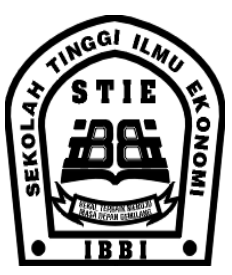

agar dapat mewujudkan peran APIP secara efektif, yaitu :Level 1 (Initial), Level 2 (Infrastructure), Level 3 (Integrated), Level 4 (Managed), Level 5 (Optimizing).

Dalam penelitian ini, peneliti menggunakan jenis data kualitatif. Yaitu data yang merupakan bentuk bukan angka, melainkan narasi deskriptif.

Sumber data penelitan merupakan data sekunder yaitu data yang biasanya berbentuk dokumen-dokumendan data primer yaitu data yang langsung dikumpulkanoleh peneliti dari sumber pertamanya dari hasilpengumpulan data mentahnya yang dilakukan oleh peneliti sendiri (Suryabrata 2015, hal. 39).

Teknik yang digunakan dalam pengumpulan data adalahTeknik wawancara, Observasi dan Teknik dokumentasi.

Adapun teknik analisis data yang digunakan dalam penelitian ini adalahdengan menggunakan metode dekskriptif, yaitu dengan cara menentukan datayang akan digunakan, mengumpulkan data yang telah ditentukan, kemudian menganalisis data sertadibandingkan dengan teori-teori, kemudian diambil suatu kesimpulandanselanjutnya memberikan saran

\section{HASIL PENELITIAN \\ Deskripsi Data}

Pengumpulan data dengan memperoleh data primer yaitu data yang diperoleh secara langsung dari objek penelitian dengan cara observasi dan dokumentasi dengan memperoleh formuir isian Kapabilitas APIP yang bersumber dari Lampiran 1 PK BPKP Nomor 16 Tahun 2015 tentang Pedoman Teknis Peningkatan Kapabilitas Aparat Pengawasan Internal Pemerintah. Dari formulir isian tersebut akan diketahui Key Procces Area (KPA) yang telah dipenuhi oleh Inspektorat Kota Tebing Tinggi untuk di nilai berdasarkan elemen-elemen Internal Audit Capability Model (IA-CM) hingga di peroleh level untuk setiap elemen yang kemudian di analisis untuk memperoleh level per unit APIP Inspektorat Kota Tebing Tinggi.

\section{Hasil Analisis Data}

ISSN 1858-3202

JURNAL

BINA AKUNTANSI

IBBI

Berdasarkan hasil analisis data berdasarkan pemenuhan Key Procces Area (KPA) pada setiap elemen, ditampilkan simpulan perolehan keseluruhan setiap elemen dapat dilihat pada tabel sebagai berikut

Tabel 1.3 Capaian Level Setiap Elemen

\begin{tabular}{|c|c|c|c|c|c|c|}
\hline No & Elemen & Key Procces Area & Level & $\begin{array}{c}\text { Pernyataan } \\
\text { Nomor }\end{array}$ & $\begin{array}{c}\text { Capaian } \\
(\%)\end{array}$ & $\begin{array}{c}\text { Capaian } \\
\text { Level } \\
\text { Elemen }\end{array}$ \\
\hline \multirow{3}{*}{1} & \multirow{3}{*}{$\begin{array}{l}\text { Peran dan Layanan } \\
\text { APIP }\end{array}$} & 1. Audit Ketaatan & 2 & \multirow{3}{*}{$1-5$} & 100.00 & \multirow{3}{*}{3} \\
\hline & & 2. Audit Kinerja & 3 & & 100.00 & \\
\hline & & 3. Layanan Konsultasi & 3 & & 100.00 & \\
\hline \multirow{5}{*}{2} & \multirow{5}{*}{ Pengelolaan SDM } & $\begin{array}{l}\text { 1. Identifikasi dan rekrutmen SDM } \\
\text { yang Kompeten }\end{array}$ & 2 & \multirow{5}{*}{ 6-8 } & 100.00 & \multirow{5}{*}{3} \\
\hline & & 2. Pengembangan profesi Individu & 2 & & 100.00 & \\
\hline & & 3. Koordinasi tim & 3 & & 100.00 & \\
\hline & & $\begin{array}{l}\text { 4. Pegawai yang berkualifikasi } \\
\text { profesional }\end{array}$ & 3 & & 100.00 & \\
\hline & & $\begin{array}{l}\text { 5. Membangun tim dan } \\
\text { kompetensinya }\end{array}$ & 3 & & 100.00 & \\
\hline \multirow{4}{*}{3} & \multirow{4}{*}{ Praktik Profesionnal } & $\begin{array}{l}\text { 1. Perencanaan Pengawasan } \\
\text { berdasarkan prioritas manajemeen }\end{array}$ & 2 & \multirow{4}{*}{$9-13$} & 100.00 & \multirow{4}{*}{2} \\
\hline & & $\begin{array}{l}\text { 2. Kerangka Kerja Praktik Profesional } \\
\text { dan Pengawasannya }\end{array}$ & 2 & & 100.00 & \\
\hline & & 3. Perencanaan audit berbasis resiko & 3 & & 75.00 & \\
\hline & & 4. Kualitas Kerangka Kerja Manajemen & 3 & & 64.28 & \\
\hline \multirow{5}{*}{4} & \multirow{5}{*}{$\begin{array}{l}\text { Akuntabilitas dan } \\
\text { Manajemen Kinerja }\end{array}$} & 1. Perencanaan Kegiatan APIP & 2 & \multirow{5}{*}{$14-21$} & 100.00 & \multirow{5}{*}{2} \\
\hline & & 2. Anggaran Operasional Kegiatan APIP & 2 & & 100.00 & \\
\hline & & 3. Pelaporan Manajemen APIP & 3 & & 100.00 & \\
\hline & & 4. Informasi Biaya & 3 & & 60.00 & \\
\hline & & 5. Pengukuran Kinerja & 3 & & 87.50 & \\
\hline \multirow{3}{*}{5} & \multirow{3}{*}{$\begin{array}{l}\text { Budaya dan } \\
\text { Hubungan Organisasi }\end{array}$} & 1. Pengelolaan Organisasi APIP & 2 & \multirow{3}{*}{$22-24$} & 100.00 & \multirow{3}{*}{3} \\
\hline & & $\begin{array}{l}\text { 2. Komponen manajemen tim yang } \\
\text { integral }\end{array}$ & 3 & & 100.00 & \\
\hline & & $\begin{array}{l}\text { 3. Koordinasi dengan pihak lain yang } \\
\text { memberikan saran dan penjaminan }\end{array}$ & 3 & & 100.00 & \\
\hline \multirow{4}{*}{6} & \multirow{4}{*}{ Struktur Tata Kelola } & 1. Hubungan Pelaporan telah & 2 & \multirow{4}{*}{$25-29$} & 100.00 & \multirow{4}{*}{3} \\
\hline & & $\begin{array}{l}\text { 2. Akses Penuh terhadap Informasi } \\
\text { Organisasi, Aset dan SDM }\end{array}$ & 2 & & 100.00 & \\
\hline & & 3. Mekanisme Pendanaan & 3 & & 100.00 & \\
\hline & & $\begin{array}{l}\text { 4. Pengawasan Manajemen terhadap } \\
\text { Kegiatan APIP }\end{array}$ & 3 & & 100.00 & \\
\hline
\end{tabular}

Capaian tingkat Kapabilitas unit APIP Inspektorat Kota Tebing Tinggi dari hasil penilaian 6 elemen sesuai standart IA-CM adalah sebagai berikut :

Tabel 1.4 Capaian Tingkat Level Kapabilitas APIP

\begin{tabular}{|c|l|c|}
\hline \multicolumn{2}{|c|}{ Elemen } & Level \\
\hline I & Peran dan Layanan APIP & 3 \\
\hline Il & Pengelolaan SDM & 3 \\
\hline Ill & Praktik Profesionnal & 2 \\
\hline $\mathbf{I V}$ & $\begin{array}{l}\text { Akuntabilitas dan Manajemen } \\
\text { Kinerja }\end{array}$ & 2 \\
\hline V & $\begin{array}{l}\text { Budaya dan Hubungan } \\
\text { Organisasi }\end{array}$ & 3 \\
\hline Vl & Struktur Tata Kelola & 3 \\
\hline \multicolumn{2}{|c|}{ Simpulan Level } & 3dcp* $^{*}$ \\
\hline
\end{tabular}

Keterangan: $*=$ dengan catatan perbaikan (dcp)

Dari tabel di atas dapat dijelaskan bahwa 4 elemen yaitu elemen "Peran dan Layanan APIP", "Pengelolaan SDM", "Budaya dan 


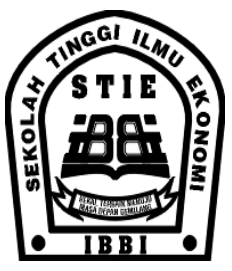

Hubungan Organisasi" dan "Struktur Tata Kelola" sudah mencapai "Level 3" sedangkan elemen "Praktik Profesional" dan elemen "Akuntabilitas dan Manejemn Kinerja" masih mencapai "Level 2". Karena elemen yang memiliki level terendah kurang dari 3, yaitu elemen "Praktik Profesional" dan elemen "Akuntabilitas dan Manejemn Kinerja" yang berada pada Level 2, maka Level Kapabilitas Unit APIP dinyatakan pada satu tingkat di atas dari level paling rendah tersebut dengan "catatan perbaikan". Sehingga dapat disimpulkan tingkat Level Kapabilitas Unit APIP Inspektorat Kota Tebing Tinggi adalah satu tingkat di atas level yang paling rendah dengan tambahan "catatan perbaikan" yaitu "Level 3 dengan catatan perbaikan" (Integrated).

\section{PEMBAHASAN}

\section{Tingkat Kapabilitas APIP pada Inspektorat Kota Tebing Tinggi Dengan Mengacu pada Standart IA-CM}

Berdasarkan penilaian kapabilitas pada Inspektorat Kota Tebing Tinggi melalui elemen-elemen StandartInternal Audit Capability Model (IA-CM), dapat disimpulkan bahwa tingkat kapabilitas Inspektorat Kota Tebing Tinggi berada pada level 3 dengan catatan perbaikan (Integrated). Inspektorat Kota Tebing Tinggi belum mencapai level 3 penuh karena masih terdapat 2 elemen yang berada pada level 2 yaitu elemen "Praktik Profesional" dan elemen "Akuntabilitas dan Manejemn Kinerja". Perlu adanya langkahlangkah perbaikan yang harus dilakukan Inspektorat Kota Tebing Tinggi untuk mencapai level 3 yang kemudian akan di bahas pada sub 3 di bagian strategi untuk meningkatan kapabilitas APIP yang belum maksimal.

Berada pada level 3 dengan catatan perbaikan (Integrated) maka dapat dikatakan bahwa APIP Inspektorat Kota Tebing Tinggi dalam pelaksanaan pengawasannya praktik profesional dan audit internal telah diterapkan secara serentak dan telah selaras dengan standar yang ditentukan. Suatu APIP yang sudah mencapai pada level 3 berarti "Telah mampu menilai efesiensi, efektivitas dan keekonomian suatu program atau kegiatan dan mampu memberikan konsultasi pada tata kelola, menejemen resiko dan pengendalian intern".

\section{Elemen yang mempengaruhi ketertinggalan Kapabilitas APIP Pada Inspektorat Tebing Tinggi}

Dari hasil penilaian kapabilitas APIP Inspektorat Kota Tebing Tinggi melalui 6 elemen menggukana Standart IA-CM menyatakan unit APIP Inspektorat Kota Tebing Tinggi berada pada level 3 dengan catatan perbaikan, yang berarti masih ada elemen yang belum terpenuhi untuk dapat mencapai Level 3 penuh. Adapun elemenelemen yang mempengaruhi ketertinggalan kapabilitas APIP mencapai level 3 adalah sebagai berikut :

a. Elemen Praktik Profesional

\section{(Profesional Practice)}

Pada elemen Praktik Profesional untuk mencapai level 3 terdapat total 4 KPA yang harus terpenuhi. Dari total $4 \mathrm{KPA}$, hanya 2 KPA yang terpenuhi yaitu KPA "Perencanaan Pengawasan berdasarkan prioritas manajemeen" dan "Kerangka Kerja Praktik Profesional dan Pengawasannya". Sedangkan 2 KPA lain nya yaitu KPA "Perencanaan audit berbasis resiko" masih terpenuhi hingga $75 \%$ dan KPA "Kualitas Kerangka Kerja Manajemen" masih terpenuhi mencapai $64,28 \%$. Adapun penjelasan KPA yang terpenuhi adalah sebagai berikut :

1) KPA : Perencanaan audit berbasis resiko InspektoratKota Tebing Tinggi belum mengidentifikasi alternatif penanganan risiko yang dilakukan oleh manajemen dan penanganan tambahan yang diperlukan untuk merespons risiko.

2) KPA : Kualitas Kerangka Kerja Manajemen

Inspektur Kota Tebing Tinggi untuk belummenerapkan upaya menjaga kualitas kegiatan pengawasan sesuai dengan pedoman telaah sejawat yang telah ditetapkan dalam rangka penjaminan kegiatan pengawasan yang telah dilaksanakan. 
b. Elemen

danManajemenKinerja (Performance Management and Accountability)

Pada elemein Akuntabilitas danManajemenKinerja untuk mencapai level 3 terdapat total 5 KPA yang harus terpenuhi. Dari total $5 \mathrm{KPA}$, hanya $3 \mathrm{KPA}$ yang terpenuhi yaitu KPA "Perencanaan Kegiatan APIP", "Anggaran Operasional Kegiatan APIP" dan "Pelaporan Manajemen APIP". Sedangkan 2 KPA lain nya yaitu KPA "Informasi Biaya" masih terpenuhi hingga $60 \%$ dan KPA "Pengukuran Kinerja" masih terpenuhi mencapai 87,50\%. Adapun penjelasan KPA yang terpenuhi adalah sebagai berikut :

1) $\mathrm{KPA}:$ Informasi Biaya

InspektoratKota Tebing Tinggi belum melakukan analisis varian biaya. analisis varian biaya dilakukan untuk memantau biaya secara berkala dan memastikan bahwa anggaran dan realisasinya masih relevan dan memadai untuk melaksanakan kegiatan pengawasan yang telah direncanakan secara efektif, efisien dan ekonomis.

2) KPA : Pengukuran Kinerja

Inspektur Kota Tebing Tinggi untuk belummenerapkan mekanisme pengumpulan data belum di atur secara formal.

\section{Strategi yang dilakukan untuk meningkatan kapabilitas APIP yang belum maksimal}

Untuk mewujudkan instruksi Presiden Republik Indonesia kepada kepala BPKP, sebagaiman tercatum dalam RPJMN 20152019 ditargetkan kapabilitas APIP K/L/P sebanyak $85 \%$ di level 3 pada Tahun 2019, melihat pencapaian Inspektorat Kota Tebing Tinggi pada tahun 2017 yang hampir maksimal hingga menempati level 3 dengan catatan perbaikan maka strategi yang $d$ butuhkan dalam meningkatkan kapabilitas APIP hanya dengan memperbaiki pemenuhan KPA pada elemen yang belum terpenuhi.

Yaitu dengan menerapkan KPA yang masih dalam proses implementasi untuk dapat memenuhi hingga mencapai $100 \%$ pencapaian keseluruhan elemen hingga memperoleh level 3 penuh. Yaitu elemen Praktik Profesional (Profesional Practice) dan Akuntabilitas danManajemenKinerja (Performance Management and Accountability) yang masih berada pada level 2, sehingga dengan memaksimalkan pemenuhan KPA pada 2 elemen tersebut hingga level 3 unit APIP Inspektorat Kota Tebing Tinggi dapat menduduki level 3 penuh.

\section{KESIMPUAN DAN SARAN}

\section{Kesimpulan}

Berdasarkan Hasil Penelitian dan Pembahasan yang telah di uraikan pada bab sebelumnya terkait Tingkat Kapabilitas Aparat Pengawasan Intern Pemerintah (APIP) menggunakan Standart Internal Audit Capability Model (IA-CM) pada Inspektorat Kota Tebing Tinggi maka dapat disimpulkan hal-hal sebagai berikut :

1. Tingkat Kapabilitas unit Aparat Pengawasan Intern Pemerintah (APIP) Inspektorat Kota Tebing Tinggi berada pada level 3 dengan catatan perbaikan (Integrated).

2. Dalam penilaian kapabilitas melalui 6 elemen sesuai Standart IA-CM, 4 elemen yaitu elemen "Peran dan Layanan APIP (Service and Role of Internal Auditing)", "Pengelolaan Sumber Daya Manusia (People Management)", "Budaya dan Hubungan Organisasi (Organization Relationship and Culture)" dan elemen "Struktur Tata Kelola (Governance Structure)" sudah mencapai level 3 sedangkan 2 elemen lain nya yaitu elemen "Paktik Profesional (Profesional Practice)" dan elemen "Akuntabilitas dan Manajemen Kinerja (Performance Management and Accountability)" masih mencapai level 2.

3. Berdasarkan hasil penilaian yang menyatakan berada pada level 3 dengan catatan perbaikan berarti unit APIP Inspektorat Kota Tebing Tinggi dalam pelaksanaan pengawasannya praktik profesional dan audit internal telah diterapkan secara serentak dan telah selaras dengan standar yang ditentukan walaupun belum sepenuhnya dikarenakan belum terpenuhinya 2 elemen yang belum 

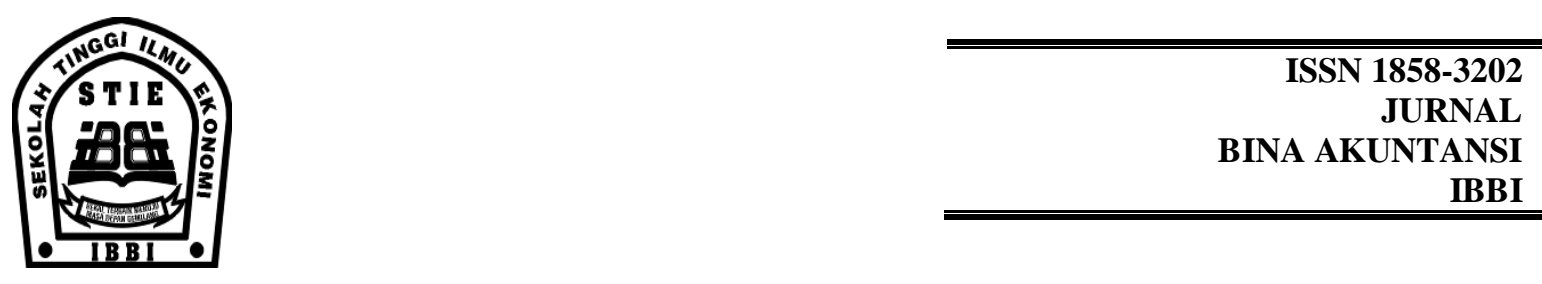

diterapkan sepenuhnya dalam unit organisasi APIP.

\section{DAFTAR PUSTAKA}

\section{Saran}

Berdasarkan hasil penelitian penulis mengenai Kapabilotas APIP di Inspektorat Kota Tebing Tinngi, penulis mengemukakan saran sebagai berikut :

1. Untuk elemen yang belum terpenuhi di akibatkan oleh beberapa KPA yang belum di diterapkan yaitu dalam 1) KPA : Perencanaan audit berbasis resiko, Inspektorat belum belum mengidentifikasi alternatif penanganan risiko yang dilakukan oleh manajemen dan penanganan tambahan yang diperlukan untuk merespons risiko; 2) KPA : Kualitas Kerangka Kerja Manajemen, Inspektorat belum menerapkan upaya menjaga kualitas kegiatan pengawasan sesuai dengan pedoman telaah sejawat yang telah ditetapkan dalam rangka penjaminan kegiatan pengawasan yang telah dilaksanakan ; 3) KPA : Informasi Biaya, belum melakukan analisis varian biaya dan pada 4) KPA : Pengukuran Kinerja, Inspektorat belummenerapkan mekanisme pengumpulan data belum di atur secara formal. Maka disarankan untuk 4 KPA yang belum di terapkan segera di terapkan agar dapat memenuhi syarat mencapai level 3 penuh.

2. Inspektorat Kota Tebing Tinggi agar mengembangkan strategi atau rencanaperbaikan yang terarah secara berkelanjutan untuk meningkatkankapabilitasnya pada area-area yang berdasarkan hasil penelitian masihmemerlukan perbaikan. Dengan tingkat kapabilitas yang memadai,diharapkan Inspektorat Kota Tebing Tinggi dapat memberikan penilaian yangindependen dan objektif atas efektivitas tata kelola di lingkunganpemerintahan Kota Tebing Tinggi, sehingga akan mendorong peningkatanefektivitas instansi pemerintah di lingkungan tersebut.
Angga Rahmana. 2016. Analisis Kapabilitas Aparat Pengawasan Internal APIP menggunakan Internal Audit Capability Model (IA-CM) Studi Kasus pada Inspektorat Kota Medan, Medan : Skripsi

Agoes, Sukrisno. 2012 Auditing, Edisi Keempat, Jakarta : Salemba Empat

Aprialiana, Mutia Silvi. 2015. Analisis Struktur Pengendalian Intern Atas Penerimaan Kas Dari Penjualan Tunai Pada Pt Sinar Bearindo Sentosa Palembang. : skripsi

Asosiasi Auditor Intern Pemerintah Indonesia, 2013. Standar Audit Intern Pemerintah Indonesia, Asosiasi Auditor Intern Pemerintah Indonesia, Jakarta.

2014. Kode Etik Auditor Intern Pemerintah Indonesia, Asosiasi AuditorIntern Pemerintah Indonesia, Jakarta.

Arens, A Alvin, Elder, Randal J., Beasley Mark S. 2008. Auditing dan Jasa Assurance. Edisi Kedua Belas. Jakarta: Erlangga. Penerjemah : Herman Wibowo.

Asward, Ismalia dan Lina. 2015. Pengaruh Mekanisme Corporate Governance terhadap Manajemen Laba dengan Pendekatan Conditionalevenue Model. Jurnal Mnajemen Teknologi. Di unduh 03 Januari 2018.

http://dx.doi.org/10126945/jmt.201 $\underline{4.14 .1 .2}$

Boynton, William C., Johnson, Raymond N. \& Kell, Walter G. 2002. ModernAuditing.Edisi Ketujuh. Jilid I. Jakarta: Erlangga 


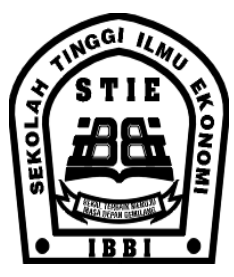

Cadbury, S. A. (2002). Corporate governance: an international view. Oxford: Oxford University Press

Dan M Guy, et al. Penerjemah: Paul A. Rajoe, dkk. 2003. Edisi 5. Auditing Jilid ke-2. Jakarta: Erlangga.

Desyana, Diana. 2017. Analisis Pelaksanaan Sistem Pelaporan PajakElektronik(E-Spt) Spt Tahunan MelaluiE-Filing Pada Kpp PratamaPematangsiantar :skripsi

Eliser Yohanes dkk. 2016. Peran Aparat Pengawasan Internal Pemerintah (APIP) dalam Penyelenggaraan Pemerintahan Daerah di Kabupaten Bulungan. Jurnal Adinistrasi. Di unduh 28 November 2017. Vol. 4(1):65-78

Eviyanti, et al. 2011. Peranan Audit Internal Dalam Mengatasi Risiko Penjualan Secara Kredit Pada PT. Thamrin Brothers Palembang. Jurnal Akuntansi. Di unduh 09 Januari 2018.

Internal Audit Capability Model (IA-CM) for The Public Sector Overview. Diakses pada 16 Desember 2017. https://na.theiia.org/iiarf/Public\%2 0Documents/Internal\%20Audit\%2 0Capability\%20Model\%20IACM\%20for\%20the\%20Public\%20

Sector\%20Overview.pdf

Jo Janse Van Rensbug. 2014. Internal Audit Capability (The South African Public Sector), Afrika Selatan : Student Paper

Komite Nasional Kebijakan Governance. 2008. Pedoman Umum Good Public Governance Indonesia. Di unduh pada 09 Januari 2015. http://www.knkg-

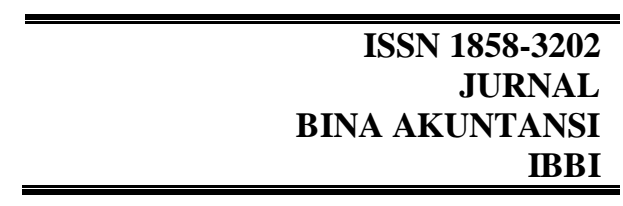

indonesia.org/dokumen/PedomanGood-Public-Governance.pdf

Kumaat, Valery G. 2010 Internal Audit, Jakarta : Erlangga

Ade Sanjaya (2015). Landasan Teori, "Pengertian Good Governance Definisi Prinsip Menurut Para Ahli”.

http://www.landasanteori.com/201 5/10/pengertian-good-governancedefinisi.html. Diakses pada 20 Desember 2017.

Lasmaya, S.Mia dan Karmila. 2011. Pengaruh Audit Internal Terhadap Efektifitas Pengelolaan Penerimaan Kas Pada Pt Bhanda Ghara Reksa Bandung. Jurnal Ekonomi, Bisnis \& Entrepreneurship. ISSN 2443-0633

Mulyadi. 2010. Auditing. Edisi Keenam. Jakarta: Salemba Empat

Nita Safitri. 2017, Analisis Kapabilitas Aparat Pengawasan Intern Pemerintah (APIP) Pemerintah Magelang (Studi Kasus Pemerintah Magelang), Yogyakarta : tesis

Nurmala, Ningsih dan Yuswar Effendy, 2015 Akuntansi Sektor Publik, Medan : Perdana Publishing

Peningkatan Kapabilitas Aparat Pengawasan Intern Pemerintah Rakornas APIP, BPKP(http://www.bpkp.go.id/kont en/2338/rakorn)

Republik Indonesia .Peraturan menteri Negara Pendayagunaan Aparatur Negara Nomor PER/05/M.PAN/03/2008 tentang Standart Audit Aparat Pengawasan Intern Pemerintah

Republik Indonesia. Peraturan Pemerintah No 192 tahun 2014 tentang Badan 
Pengawasan Keuangan dan Pembangunan Pasal 2

Nomor 60 Tahun 2008 tentang SistemPengendalian Intern Pemerintah (SPIP).

Republik Indonesia. Peraturan Kepala BPKP Tahun 2015 tentang Pedoman Teknis Monitoring Tingkat Kapabilitas Aparat Pengawasan Intern Pemerintah

Sadikin, Dikdik. 2016 Peningkatan Kapabilitas Aparat Pengawasan Intern Pemerintah, Bogor : Pusdiklatwas BPKP

Sawyer, Lawrence B, dkk 2005, Audit Internal, Edisi Lima, Buku Satu, Salemba Empat, Jakarta.

Sugiyono. 2016. Metode Penelitian Kuantitatif Kualitatif Dan R\&D. Bandung : Alfabeta

Sumadi Suryabrata, (2015). Metodologi Penelitian (Edisi 2). Jakarta: PT.RajaGrafindo Persada

The Institute Of Internal Auditor. Definition of Internal Auditor. Diakses pada $24 \quad$ December 2017. https://na.theiia.org/standardsguidance/mandatory guidance/Pages/Definition-ofInternal-Auditing.aspx

Tommy Indra Heriyanto. 2016. Analisis Kapabilitas APIP berdasarkan Standart IA-CM Pada Pemerintah Kota Padang Panjang, Padang : Skripsi

Vera Neldy. 2016. Analisis Peningkatan Kapabilitas APIP dengan menggunakan IA-CM pada Inspektorat Kabupaten Solok, Solok : Skripsi
Wahyubroto, Antonius M dan Ronny H.M. 2017. Implementasi Prinsip-Prinsip Good Corporate Governance Pada Perusahaan Di Kota Gresik. Jurnal Manajemen Bisnis. AGORA Vol. 5, No. 3, (2017)

Yudhi Setiawan. 2015, Evaluasi Kapabilitas APIP menggunakan Internal Audit Capability Model (IA-CM) sebagai Pengawasan Intern yang Efektif (Studi Kasus pada Auditor Internal Inspektorat Kota Palembang), Palembang :Skripsi 